\title{
BMJ A descriptive epidemiological study on OPen the patterns of occupational injuries in a coastal area and a mountain area in Southern China
}

\author{
Liping Li, ${ }^{1}$ Xiaojian Liu, ${ }^{1,2}$ Bernard C K Choi, ${ }^{1,3}$ Yaogui Lu, ${ }^{1}$ Min Yu ${ }^{4}$
}

To cite: Li L, Liu X, Choi BCK, et al. A descriptive epidemiological study on the patterns of occupational injuries in a coastal area and a mountain area in Southern China. BMJ Open 2012;2:e000965.

doi:10.1136/

bmjopen-2012-000965

- Prepublication history for this paper is available online. To view these files please visit the journal online (http:// dx.doi.org/10.1136/ bmjopen-2012-000965).

Received 10 February 2012 Accepted 14 May 2012

This final article is available for use under the terms of the Creative Commons Attribution Non-Commercial 2.0 Licence; see http://bmjopen.bmj.com

${ }^{1}$ Injury Prevention Research Centre, Medical College of Shantou University, Shantou, China

${ }^{2}$ Shenzhen Centre for Disease Prevention and Control, Shenzhen, China ${ }^{3}$ Department of Epidemiology and Community Medicine, University of Ottawa, Ottawa, Ontario, Canada

${ }^{4}$ Zhejiang Provincial Centre for Disease Prevention and Control, Hangzhou, China

Correspondence to Dr Bernard Choi; bernard.choi@utoronto.ca

\section{ABSTRACT}

Objectives: This study compared patterns of occupational injuries in two different areas, coastal (industrial) and mountain (agricultural), in Southern China to provide information for development of occupational injury prevention measures in China.

Design: Descriptive epidemiological study.

Setting: Data were obtained from the Hospital Injury Surveillance System based on hospital data collected from 1 April 2006 to 31 March 2008

Participants: Cases of occupational injury, defined as injury that occurred when the activity indicated was work.

Outcome measures: Distribution and differences of patterns of occupational injuries between the two areas.

Results: Men were more likely than women to experience occupational injuries, and there was no difference in the two areas $(p=0.112)$. In the coastal area, occupational injury occurred more in the 21-30year age group, but in the mountain area, it was the $41-50$-year age group $(p<0.001)$. Occupational injuries in the two areas differed by location of hometown, education and occupation (all $p<0.001$ ). Occupational injuries peaked differently in the month of the year in the two areas $(p<0.001)$. Industrial and construction areas were the most frequent locations where occupational injuries occurred $(p<0.001)$. Most occupational injuries were unintentional and not serious, and patients could go home after treatment. The two areas also differed in external causes and consequences of occupational injuries.

Conclusions: The differing patterns of occupational injuries in the coastal and mountain areas in Southern China suggest that different preventive measures should be developed. Results are relevant to other developing countries that have industrial and agricultural areas.

\section{INTRODUCTION}

Occupational injury is a serious problem affecting the health of workers. The International Labour Organization (ILO) estimates that about 2.2 million people die globally

\section{ARTICLE SUMMARY}

Article focus

- Occupational injury is a serious problem causing 350000 deaths and 270 million serious non-fatal injuries globally every year.

- This study is the first attempt in China to compare the characteristics and risk factors of occupational injuries in a coastal area (industrial) and a mountain area (agricultural).

- Occupational injury patterns were found to differ in the two areas, in terms of location of hometown, education, occupation, month of the year, location of injuries, external causes and consequences.

Key messages

- Our findings provide important information for developing occupational injury prevention programmes in industrial and agricultural areas.

- Accumulation of occupational injury studies steadily builds the epidemiological information base on which to develop interventions.

- Identification of the local geographic patterns of occupational injuries helps to import existing proven interventions from other similar geographic areas.

Strengths and limitations of this study

n The Hospital Injury Surveillance System that we established in Southern China has started to produce useful data for occupational injury prevention.

- The system still lacks important useful information such as full occupational history, evaluation measures of data accuracy and completeness, and rate information.

every year from occupational injury and illness. Of this total, about 350000 deaths are caused by fatal occupational injuries. The global workforce of 2.8 billion workers also experience about 270 million serious nonfatal injuries and 160 million work-related diseases. ${ }^{1}$ The total cost of occupational accidents and work-related diseases represents $4 \%$ of the gross national product or 
approximately US\$1.36 trillion worldwide. ${ }^{2}$ Occupational injury is serious in China. According to the ILO, fatal occupational injuries in China accounts for $26 \%$ of the world total. ${ }^{1}$

In China, government and researchers have been taking steps to understand and prevent occupational injuries. Some research on occupational injuries has been published. ${ }^{3-7}$ To deal with missing data and underreporting, methodological research has been published on the use of the capture-recapture method. ${ }^{89}$ An injury surveillance system was set up in China to track the pattern of occupational injuries, and it has been effective in preventing injuries. ${ }^{10-12}$

The economy in China is more developed in the south than in the north, especially in the highly industrial coastal areas, which attract migrant workers from other provinces. As most of these migrant workers are young and inexperienced job seekers, a high level of occupational injuries have been reported and cannot be neglected. ${ }^{13} 14$

The patterns of occupational injuries differ between developed and developing countries. ${ }^{15}$ This suggests that their patterns could be different between the more developed (coastal) and less developed (mountain) areas in Southern China. The coastal area is highly industrialised, while the mountain area is mainly agricultural. The coastal and mountain areas were chosen for the study because they represent the two major types of economic development in China. They are expected to lead to different types and patterns of occupational injuries. Our study is the first attempt in China to compare the characteristics and risk factors of occupational injuries in a coastal area and a mountain area in order to provide further understanding and a scientific basis for the prevention of occupational injuries in Southern China. The study was based on the Hospital Injury Surveillance System we have established in Southern China.

\section{METHODS}

\section{Case identification}

Injury cases were defined as first-time visits to the hospital due to a particular injury, and the activity when the injury occurred was work.

\section{Data collection}

Injury surveillance was based on hospital data collected in two areas of Southern China, a coastal and a mountain area. Ethical approval was granted by the Shantou University research ethics review board. No patient consent form was required as the study was based on routine administrative data only. Data were collected from 1 April 2006 to 31 March 2008.

Hospital staff completed the injury report forms including patient demographics, date and time of admission, details about the injury cause and location, the injury intention and severity, diagnoses, treatment procedures, and discharge information. Every month, researchers collected the reporting forms. Data were entered into a database, and injury diagnosis and causes were coded by trained research staff using the 10th revision of International Classification Disease.

\section{Quality control}

Hospital staff who completed report forms were trained by researchers of the project. Every week, researchers reviewed the injury report forms to find problems and provide suggestions to improve. The data were entered into the research database by double keying to reduce error.

\section{Data analysis}

Data analysis involved use of SPSS V.15.0 for Windows (SPSS Inc.). Descriptive statistics were used. $\chi^{2}$ Analysis was used to compare differences between the mountain and coastal areas. A p $<0.05$ (two sided) was considered statistically significant.

\section{RESULTS}

Over the 2-year period, 8929 occupational injuries were identified, of which 7400 (82.88\%) were men. The average age of the injured cases was 38.37 years $(\mathrm{SD}=12.36)$. The age group 31-40 years experienced the most occupational injuries, accounting for $29.2 \%$ of the injured patients.

\section{Sex and age differences between coastal and mountain} areas in cases of occupational injuries

There was no sex difference. In the coastal area, there were 3230 male occupational injuries $(81.86 \%$ of all cases) as compared with 5699 male occupational injuries in the mountain area $(83.45 \%)$, with no statistically significant difference between the two areas $(p=0.112)$.

In the coastal area, the average age of injured patients was 32.10 years $\quad(\mathrm{SD}=11.34)$ as compared with 41.91 years $(\mathrm{SD}=11.47)$ in the mountain area $(\mathrm{p}<0.001)$. In the coastal area, occupational injuries peaked in the age group 21-30 years, whereas in the mountain area, the peak occurred in the age group 41-50 years $(\mathrm{p}<0.001)$ (figure 1).

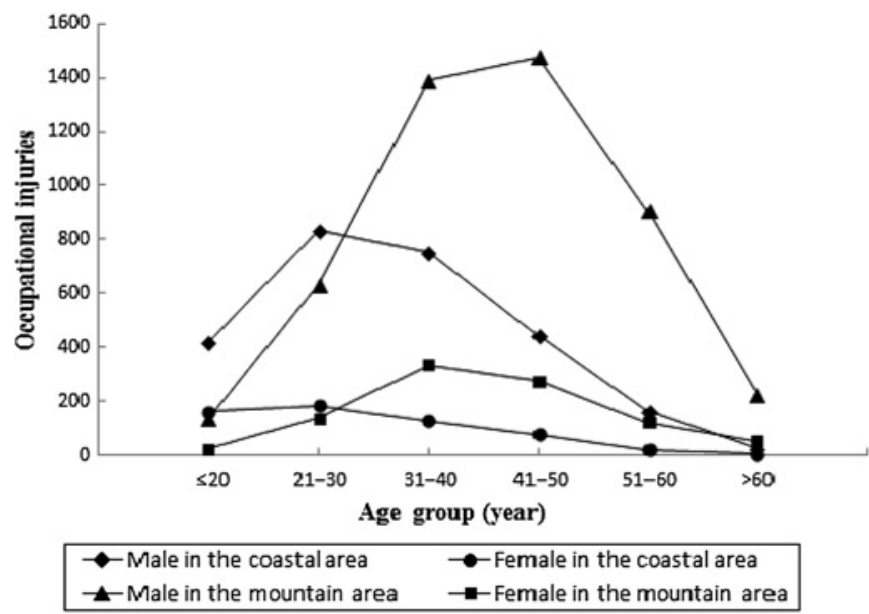

Figure 1 Distribution of occupational injuries by age and sex in a costal area and a mountain area in Southern China, 2006-2008. 
Differences between coastal and mountain areas in characteristics of cases of occupational injuries

In the coastal area, injured cases were mostly from the local city (54.6\%) and other provinces $(39.9 \%)$, whereas in the mountain area, $88.4 \%$ were from the local city $(\mathrm{p}<0.001)$ (table 1$)$. The education of injured cases differed between the coastal and mountain areas $(\mathrm{p}<0.001)$. In the coastal area, $59.0 \%$ of patients completed junior middle school and $19.0 \%$ completed primary school. In the mountain area, fewer injured patients had completed junior middle school
$(43.9 \%)$ and more had completed primary school $(29.7 \%)$.

Occupations differed between injured cases in the two areas $(p<0.001)$. In the coastal area, patients worked largely in production, transport and equipment operation $(57.0 \%)$; professional and technical $(14.5 \%)$ and commercial and service sector $(11.0 \%)$. In the mountain area, injured patients worked mostly in production, transport and equipment operation $(37.3 \%)$; agriculture, grazing, fishing and water conservancy $(33.8 \%)$ and professional and technical $(11.0 \%)$.

Table 1 Comparison of characteristics of cases of occupational injuries in a coastal area and a mountain area in Southern China, 2006-2008

\begin{tabular}{|c|c|c|c|}
\hline Characteristics & Coastal area, N (\%) & Mountain area, $\mathrm{N}(\%)$ & p Value \\
\hline \multicolumn{4}{|l|}{ Hometown } \\
\hline Local city & $1732(54.6)$ & $5038(88.4)$ & \multirow[t]{3}{*}{0.000} \\
\hline Other cities in local province & $173(5.5)$ & $188(3.3)$ & \\
\hline Other provinces & 1267 (39.9) & $473(8.3)$ & \\
\hline \multicolumn{4}{|l|}{ Education } \\
\hline None & $77(2.4)$ & $573(10.15)$ & \multirow[t]{6}{*}{0.000} \\
\hline Primary school (years 1-6) & $605(19.0)$ & $1690(29.7)$ & \\
\hline Junior middle school (years 7-9) & $1874(59.0)$ & 2499 (43.9) & \\
\hline Senior middle school (years 10-12) & $524(16.5)$ & $828(14.5)$ & \\
\hline College & $77(2.4)$ & $78(1.4)$ & \\
\hline University & $20(0.6)$ & $26(0.5)$ & \\
\hline \multicolumn{4}{|l|}{ Occupation } \\
\hline Professional and technical & $461(14.5)$ & $628(11.0)$ & \multirow[t]{6}{*}{0.000} \\
\hline Clerical & $134(4.2)$ & $175(3.1)$ & \\
\hline Commercial and service sector & $350(11.0)$ & $264(4.6)$ & \\
\hline Agriculture, grazing, fishing and water conservancy & $232(7.3)$ & 1927 (33.8) & \\
\hline Production, transport and equipment operation & $1817(57.0)$ & 2127 (37.3) & \\
\hline Others & $195(6.1)$ & $578(10.1)$ & \\
\hline \multicolumn{4}{|l|}{ Location of accident } \\
\hline Home & $41(1.3)$ & $132(2.3)$ & \multirow[t]{10}{*}{0.000} \\
\hline $\begin{array}{l}\text { Public residential places } \\
\text { (dormitory, old age home, prison, etc) }\end{array}$ & $124(3.8)$ & $172(3.0)$ & \\
\hline School and public places & $55(1.7)$ & $77(1.4)$ & \\
\hline Sports places & $4(0.1)$ & $8(0.1)$ & \\
\hline Roads and streets & $167(5.2)$ & $283(5.0)$ & \\
\hline $\begin{array}{l}\text { Trade and service places (airport, bank, hotel, } \\
\text { shop, office building, etc) }\end{array}$ & $377(11.7)$ & $321(5.6)$ & \\
\hline Industry and construction places & $2282(70.7)$ & 3804 (66.7) & \\
\hline Farms and field & $45(1.4)$ & $855(15.0)$ & \\
\hline Other places & $124(3.8)$ & $35(0.6)$ & \\
\hline Unknown & $10(0.3)$ & $12(0.2)$ & \\
\hline \multicolumn{4}{|l|}{ Intent } \\
\hline Unintentional & $2812(87.7)$ & $5403(94.8)$ & \multirow[t]{3}{*}{0.000} \\
\hline Intentional (attack, violence) & $385(12.0)$ & $287(5.0)$ & \\
\hline Suicide/unknown & $8(0.2)$ & $9(0.2)$ & \\
\hline \multicolumn{4}{|l|}{ Severity } \\
\hline Mild & $2247(70.0)$ & $4681(82.1)$ & \multirow[t]{3}{*}{0.000} \\
\hline Moderate & $781(24.3)$ & $918(16.1)$ & \\
\hline Severe & $184(5.7)$ & $100(1.8)$ & \\
\hline \multicolumn{4}{|l|}{ Outcome } \\
\hline Going home after treatment & $2462(77.5)$ & 5087 (89.3) & \multirow[t]{4}{*}{0.000} \\
\hline $\begin{array}{l}\text { Observation, hospitalisation or transfer } \\
\text { to another institution }\end{array}$ & $693(21.8)$ & $575(10.1)$ & \\
\hline Death & $8(0.3)$ & $8(0.1)$ & \\
\hline Unknown & $15(0.5)$ & $29(0.5)$ & \\
\hline
\end{tabular}


Statistically significant differences between cases in the coastal and mountain areas were also found in location of accident, intent, severity and outcome (table 1). In the coastal area, the leading locations where occupational injury occurred were industry and construction places $(70.7 \%)$, and trade and service places $(11.7 \%)$, whereas in the mountain area, the predominant places were industry and construction places $(66.7 \%)$, and farms and field $(15.0 \%)(p<0.001)$. Most occupational injuries were unintentional in both areas $(87.7 \%$ in the coastal area and $94.8 \%$ in the mountain area) $(\mathrm{p}<0.001)$. Also different was severity of occupational injury $(p<0.001)$. Most occupational injuries were mild and moderate in the two areas $(70.0 \%$ and $24.3 \%$ in the coastal area and $82.1 \%$ and $16.1 \%$ in the mountain area, respectively). In the coastal area, most patients with occupational injuries could go home after treatment $(77.5 \%)$ and some were kept for observation, hospitalisation or transfer (21.8\%), whereas in the mountain area, $89.3 \%$ of patients could go home after treatment and $10.1 \%$ were kept for observation, hospitalisation or transfer $(\mathrm{p}<0.001)$. Eight fatalities occurred with occupational injuries in each of the two areas (table 1).

Time of occurrence of occupational injuries in the coastal and mountain areas

With respect to month of the year, occupational injuries occurred every month but differed between coastal area and mountain area $(p<0.001)$ (figure 2$)$. There were two peaks in a year in the occurrence of occupational injuries in the two areas. May and November were the peak months in the coastal area and April and September in the mountain area. Occupational injures were low in February in the two areas.

With respect to day of the week, occupational injuries occurred more frequently towards beginning of the work week (Mondays and Tuesdays) (figure 3). Occupational injuries more likely occurred on weekdays $(72.8 \%$ in the coastal area and $73.3 \%$ in the mountain area), with no significant difference between the two areas $(\mathrm{p}=0.662)$. With respect to time of the day on a $24 \mathrm{~h}$ clock, occurrence of injury differed between the two areas

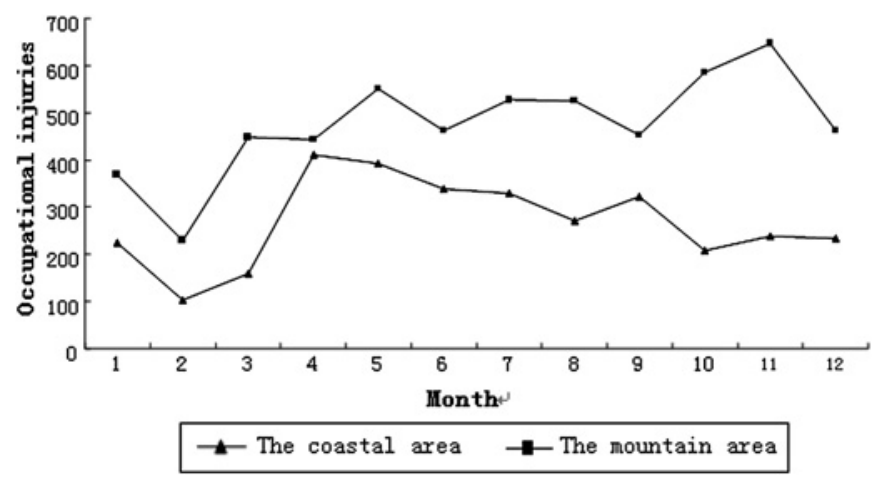

Figure 2 Distribution of occupational injuries by month of the year in a costal area and a mountain area in Southern China, 2006-2008.

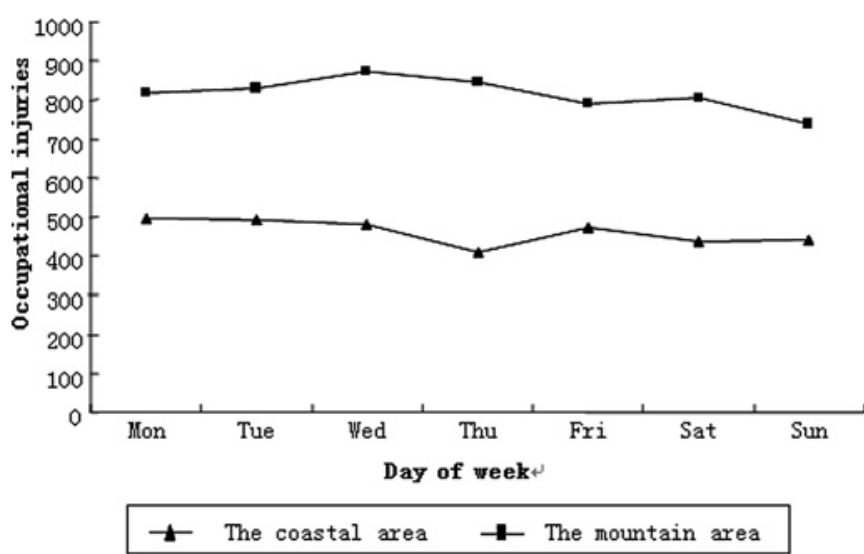

Figure 3 Distribution of occupational injuries by day of the week in a costal area and a mountain area in Southern China, 2006-2008.

$(\mathrm{p}<0.001)$. The peak times were $10: 00$ and $16: 00 \mathrm{~h}$ in the coastal area and 9:00 and 15:00 $\mathrm{h}$ in the mountain area (figure 4).

The external causes and consequences of occupational injuries in the coastal and mountain areas of Southern China The external cause codes of occupational injuries differed between the two areas. In the coastal area, the five leading external causes were contact with other and unspecified machinery (W31); being struck by or against other objects (W22); assault by bodily force (Y04); contact with a knife, sword or dagger (W26) and being struck by a thrown, projected or falling object (W20). In the mountain area, the five leading external causes were unspecified falls (W19); exposure to other and unspecified inanimate mechanical forces (W49); contact with a knife, sword or dagger (W26); contact with other and unspecified heat or hot substances (X19) and assault by a blunt object (Y00) (table 2).

The consequence codes of occupational injuries differed between the two areas. Although the first leading consequence code was open wounds of the wrist or hand (S61) in both areas, the other four leading consequence codes differed. In the coastal area, the second to fifth leading consequences were open wounds of the head (S01), crushing injury of the wrist or hand (S67), superficial injury involving multiple body parts (T00) and open wound of the ankle or foot (S91). In the mountain area, they were superficial injury of the thorax (S20), superficial injury involving multiple body parts (T00), injury to the eye or orbit (S05) and open wound of the head (S01) (table 3).

\section{DISCUSSION AND CONCLUSIONS}

Occupational injuries are related to industrial and economic growth, but they also represent a significant economic cost for the society. ${ }^{2}$ There are many migrant workers working in various factories and enterprises in Southern China, so occupational injuries are a particular issue and concern. This study, based on data from our Hospital Injury Surveillance System, explored and 
Figure 4 Distribution of occupational injuries by time of the day in a costal area and a mountain area in Southern China, 2006-2008.

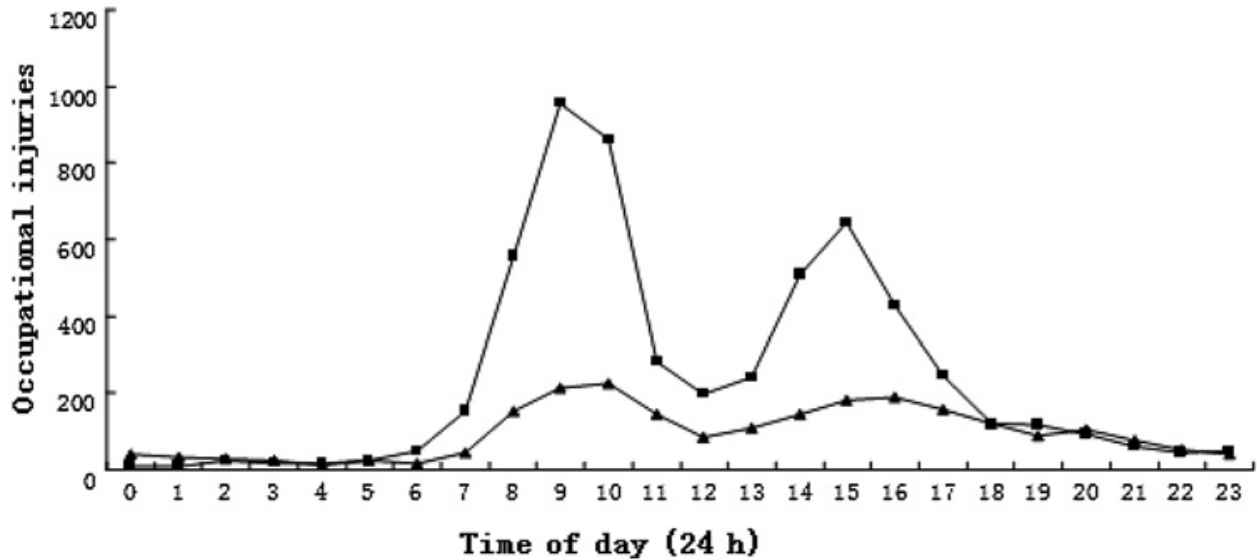

$\rightarrow$ The coastal area $\rightarrow-$ The mountain area compared patterns of occupational injuries in a coastal area and a mountain area in Southern China. Our study results have provided important information for formulating strategies and measures for the prevention of occupational injuries.

\section{Demographic characteristics}

Men are more likely to experience occupational injuries, particularly in the age group 20-40 years. These results were similar to other studies. ${ }^{12-14}{ }^{16-18}$ We found that the injury cases in the coastal area were younger than those in the mountain area. This could be the result of more migrant workers in the coastal area, who are mostly young men. ${ }^{12}$

More than half of the patients with occupational injuries were from the local city. About one-third of the patients were from other provinces in the coastal area, a result similar to findings for occupational injuries in another study. ${ }^{14}$ Migrant workers constitute a big proportion of the working population in the coastal area.

Those who suffered occupational injuries had low educational levels; almost all had only primary or junior middle school education, again similar to other findings. ${ }^{13} 14$ The low education level likely leads to lack of knowledge about self-protection and increases the danger at work.
Time of occupational injuries

Seasonal variation of occupational injuries has been demonstrated in the industries. ${ }^{4}{ }^{14}$ Our study found that occupational injuries occurred the least often in February, which coincides with the Chinese national holiday of the Spring Festival when industries and factories are closed and many migrant workers go home for the holiday. The peak month of occupational injuries in the two areas, however, differed: May and November in the coastal area and April and September in the mountain area. Issues such as climate and type of industry will need further research.

Occupational injuries showed two peak times during the day in the two areas, with little difference between areas. The peak times (10:00 and 16:00 $\mathrm{h}$ in the coastal area and 9:00 and 15:00 $\mathrm{h}$ in the mountain area) were similar to findings elsewhere, ${ }^{12}{ }^{19}$ which suggests that the dangerous time is at the beginning of the work shift when operation starts for the day and towards the end when attention span is low.

Occupational injuries occurred more frequently during beginning of the work week (Mondays and Tuesdays) in both the coastal and mountain areas, a result similar to the findings in Canada by Choi et al. ${ }^{20}$ However, the Friday peak observed in Canada was only found in the coastal area but not in the mountainous area.

Table 2 The five leading external causes with their code and percentage of occupational injuries in a coastal area and a mountain area in Southern China, 2006-2008

\begin{tabular}{lll}
\hline Rank & Coastal area (\%) & Mountain area (\%) \\
\hline 1 & $\begin{array}{l}\text { Contact with other and } \\
\text { unspecified machinery (W31) (20.6) } \\
\text { Being struck by or against other and } \\
\text { unspecified objects (W22) (6.3) } \\
\text { Assault by bodily force (Y04) (6.2) }\end{array}$ & Unspecified falls (W19) (34.0) \\
3 & $\begin{array}{l}\text { Exposure to other and unspecified } \\
\text { inanimate mechanical forces (W49) (33.9) } \\
\text { Contact with a knife, sword or } \\
\text { dagger (W26) (6.1) } \\
\text { Being struck by a thrown, } \\
\text { projected or falling object (W20) (5.9) }\end{array}$ & $\begin{array}{l}\text { dagger (W26) (11.1) } \\
\text { Contact with other and unspecified } \\
5\end{array}$ \\
\hline
\end{tabular}


Table 3 The five leading consequences with their code and percentage of occupational injuries in a coastal area and a mountain area in Southern China, 2006-2008

\begin{tabular}{|c|c|c|}
\hline Rank & Coastal area (\%) & Mountain area (\%) \\
\hline 1 & Open wound of the wrist or hand (S61) (23.5) & Open wound of the wrist or hand (S61) (9.8) \\
\hline 2 & Open wound of the head (S01) (9.6) & Superficial injury of the thorax (S20) (6.9) \\
\hline 3 & Crushing injury of the wrist or hand (S67) (8.3) & $\begin{array}{l}\text { Superficial injury involving multiple body } \\
\text { parts (TO0) (6.3) }\end{array}$ \\
\hline 4 & Superficial injury involving multiple body parts (T00) (4.7) & Injury to the eye or orbit (S05) (5.0) \\
\hline 5 & Open wound of the ankle or foot (S91) (3.9) & Open wound of the head (S01) (5.0) \\
\hline
\end{tabular}

\section{Injury characteristics}

In the coastal and mountain areas, the largest proportion of occupational injuries occurred in production, transport and equipment operations. This result is similar to other research. ${ }^{21}{ }^{22}$ Construction industries probably present a major risk in this occupational category, and those injuries could be prevented or minimised by personal protective equipment. In the mountain area, almost one-third of the injured patients were farmers, and farms and field were in addition an important location for occupational injuries.

Most of the occupational injuries in both areas were unintentional and minor, and patients could go home after treatment. Again this is similar to results from Ma et al. ${ }^{12} \mathrm{~A}$ lot of the research has focused on fatal occupational injuries. However, non-fatal injuries are more frequent and cause more disease burden ${ }^{1}$ and should not be neglected.

The leading external causes of occupational injuries in the two areas differed. The leading external cause in the coastal area was contact with other and unspecified machinery $(20.6 \%)$. Research has showed that injury by machinery is the most frequent type of occupational injury. ${ }^{18}$ The leading external cause in the mountain area was falls $(34.0 \%)$, which is similar to findings in other studies. ${ }^{16}{ }^{23}$ Falls have been recognised as a major threat to the safety of individuals in industry and also in daily living. ${ }^{24}$ With respect to the consequences of injury, open wounds of the wrist and hand are the most frequent, which is similar to other findings in China ${ }^{5} 12$ and in other countries. ${ }^{16}$ The wrist and hand are the most used body parts at work and will need particular protection.

China has seen rapid economic growth in recent decades and the associated increase in occupational injuries. The main strength of our study is that it was the first in China to examine occupational injuries in a coastal area and a mountain area. The two areas were selected to represent the two major types of economies (industrial and agricultural) in China, so that our findings are likely to be relevant to other parts of China. Additionally, the study was a first attempt to use a routine administrative database (Hospital Injury Surveillance System) for the development of occupational injury prevention strategies. The database has built-in data quality control mechanisms.
There are limitations in the study. The Hospital Injury Surveillance System we used in this study targets all kinds of injuries, not just occupational injuries. Therefore, it lacks sufficient detailed information on the type and years of work and can only provide limited information for preventive measures at work. Also, while some quality control measures were put in place to promote accuracy in data collection, no quantitative information was available in the surveillance system to describe the accuracy (reliability and validity) of the case reports or completion rates. Furthermore, presentation of rate information within demographic and occupational subgroups would be desirable, but this information was not available in the surveillance system.

Our study does provide some important baseline information for improving worker safety in China. The differences in the patterns of occupational injuries observed in the coastal industrial area and a mountain agricultural area in Southern China provide good evidence for diversified prevention strategies in different areas and settings. Accumulation of descriptive studies of occupational injuries like ours steadily builds the epidemiological information base on which to develop interventions. Effective intervention approaches may already exist for many of the injuries observed. Identification of the local geographic patterns of occupational injuries helps to import proven interventions from other similar geographic areas.

Future work in China should focus on establishing a more comprehensive occupational injury surveillance system. This can be based on the Thai experience in the recording, notification, compilation and classification of occupational injuries, carried out by the ILO. ${ }^{25}$ Innovative injury prevention measures can also be generated from brainstorming sessions of experts, similar to the prioritising workshop conducted by the Pan American Health Organization. ${ }^{26}$ Results of this study are relevant to other developing countries that have more developed (industrial) and less developed (agricultural) areas.

Acknowledgements We gratefully acknowledge the staff of the Injury Surveillance Project in Shantou and Changshan for data support.

Contributors $\mathrm{LL}$ conceived the study. $\mathrm{LL}, \mathrm{XL}$ and $\mathrm{BC}$ designed the protocol. $\mathrm{LL}$, $\mathrm{XL}, \mathrm{YL}$ and $\mathrm{MY}$ contributed to the data collection. $\mathrm{YL}$ and $\mathrm{MY}$ analysed the data. $L L$ and $B C$ wrote the first draft of the manuscript, and all authors contributed to the subsequent writing, critical review and revision of the manuscript. All authors contributed to the interpretation of the results and approved the final version. 
Funding The study was funded by the National Natural Science Foundation of China (No. 30571613).

Competing interests None.

Ethics approval Ethics approval was provided by the Shantou University research ethics review board

Provenance and peer review Not commissioned; externally peer reviewed.

Data sharing statement There are no additional unpublished data from the study available for data sharing.

\section{REFERENCES}

1. Takala J. Introductory Report: Decent Work-Safe Work. Geneva: International Labour Office, 2005:6-10.

2. Hämäläinen $P$. The effect of globalization on occupational accidents. Saf Sci 2009:47:733-42.

3. Xia ZL, Courtney TK, Sorock GS, et al. Fatal occupational injuries in a new development area in the People's Republic of China. J Occup Environ Med 2000;42:917-22.

4. Liu XR, Yang JG, Shen J, et al. Epidemiological study of occupational injuries in a new chemical industrial zone during the period of 1993 2002. Industry Health Occup Dis 2003;29:321-5

5. Shi X, Ye D. An epidemiological survey on occupation injury in a non ferrous metal company, 1980 1999. Chin J Dis Control Prev 2004;8:543-5.

6. Liu J, Gao X, Xiaofeng L, et al. Epidemiological study on occupational injury in one port enterprise. Chinese J Public Health 2005;21:997.

7. Yue $Q$, Lan $Y$. Epidemiological study on occupational injury during 1995 2004 in an iron factory. Mod Prev Med 2006;33:2363-6.

8. Hu W, Zhou A. Application of Capture-mark-recapture method on investigating unreported occupational injury. Chin J Ind Med 2005:18:40-1.

9. Hu W. Research progress on epidemiological methods of occupational injuries. Foreign Med Sci (Section Hygiene) 2002;29:174-7.

10. Amell TK, Kumar S, Rosser BW. Ergonomics, loss management, and occupational and illness surveillance, Part 2: injury and illness incident profile. Sample data. Int J Ind Ergon 2002;29:199-210.

11. Perry MJ, Sun BX, Zhang HX, et al. Emergency department surveillance of occupational injuries in Shanghai's Putuo District, People's Republic of China. Ann Epidemiol 2005;15:351-7.
12. Ma W, Peng J, Liang X, et al. Analysis on epidemiological characteristics of occupational injury among workers in different economic regions in Guangdong province. South China J Prev Med 2007;33:5-8.

13. Peng J, Zhou H, Zhou H, et al. Epidemiologic characteristic of nonfatal occupational injuries in mental manufacturing industry. Chin $J$ Public Health 2007;23:329-30.

14. Chen RC, Wang MQ, Cui R, et al. Epidemiological characteristics of the Occupationally injured population in the Foreign Electron industry. Occup Health 2008;24:1351-4.

15. Concha M, Nelson I, Fingerhut $\mathrm{M}$, et al. The global burden due to occupational injury. Am J Ind Med 2005;48:470-81.

16. Roudsari S, Ghodsi M. Occupational injuries in Tehran. Injury 2005;36:33-9.

17. Lin YH, Chen CY, Luo JL. Gender and age distribution of occupational fatalities in Taiwan. Accid Anal Prev 2008;4:1604-10.

18. Ma J, Yu Y. Occupational safety research and influencing factors. Occup Health 2007;23:59-60.

19. Shi $X$, Wang $Y$. The application of circular distribution test in the analysis of occupational injury. Chin J Dis Control Prev 2006;10:30-2.

20. Choi BCK, Levitsky M, Lloyd RD, et al. Patterns and risk factors for sprains and strains in Ontario, Canada, 1990: an analysis of the workplace health and safety agency data base. J Occup Envion Med 1996;38:379-89.

21. Ong CN, Phoon WO, Tan TC, et al. A study of work injuries in eight Asian countries. Ann Acad Med Singapore 1984;13:429-34.

22. Marika $L$, Henk $M$, Jorma $L$, et al. The Effectiveness of interventions for preventing injuries in the construction industry. Am J Prev Med 2008;35:77-84

23. Noe R, Rocha J, Clavel C, et al. Occupational injuries identified by an emergency department based injury surveillance system in Nicaragua. Inj Prev 2004;10:227-32.

24. Yoon Y, Thurmon L. Nonfatal occupational injuries associated with slips and falls in the United States. Int J Ind Ergon 2006;36:83-92.

25. Choi BCK. Recording, notification, compilation, and classification of statistics of occupational accidents and diseases: the Thai experience. J Occup Envion Med 1996;38:1151-60.

26. Choi BCK, Eijkemans GM, Tennassee LM. Prioritization of occupational sentinel health events for workplace health and hazard surveillance: the Pan American Health Organization experience. $J$ Occup Envion Med 2001;43:147-57. 